\title{
Improving Quality Distribution Systems Power with Renewable Energy Sources Connected to the Grid
}

\author{
Manaf Hassan Nezhad ${ }^{1}$ \\ Young Researchers and Elite Club, Sardasht branch, Islamic Azad University, Sardasht, \\ Iran
}

\begin{abstract}
In the last two decades Power Quality increasingly has been focused attention on power companies and subscribers. This phrase (power quality) as an inclusive concept is raised for a variety of power system disturbances. In recent years, new methods offered for improving power quality including the use of active filters, passive or hybrid. Due to the advantages and the growing use of renewable energy sources connected to the distribution grids, in the proposed system its aim is using renewable energy sources for power quality improvement in this study, the solar arrays have been used as sources for renewable energy. In this paper, we studied conducted researches in the field, a fuzzy controller is provided to control the converter signals connected to the PCC and DC link. The purpose of controller design is supplying unbalanced flow for non-linear loads on the grid that they have caused streaming on the grid to exit from the sine. This controller not only as an active power filter works pretty well, but current harmonic network, will improve by applying renewable energy sources.
\end{abstract}

Key words: power quality, controller-phase, non-linear loads, renewable energy sources, PCC Connection point.

\section{Introduction}

Power distribution systems need high power quality for the transmission of power to the connected loads in different parts of the system. Also according to the current status of renewable energy sources and conventional connected of these sources to the distribution systems, we can examine power quality issues from a new perspective. It is estimated that the loss caused by power quality disturbances only in the United States every year is about $\$ 100$ billion. Therefore, the investment to deal with this distortion is much less of damages. Undoubtedly, the quality of the electrical energy production is better now than in the past. In addition, distribution and transmission networks have been broader and they benefit from new and reliable technologies. So why terms of quality has been more important and today it is followed more seriously and extensive research is done about it? In fact we must examine the answer of this problem from two aspects. First the extensive of power networks has led to a variety of non-linear loads on the grid be scattered by nature of non- sinusoidal waveforms. This causes deviation from the ideal sinusoidal waveform and it creates power quality

\footnotetext{
${ }^{1}$ Email: $\underline{\text { m.h.nezhad9820@ gmail.com }}$
} 
disturbances. On the other hand, today's sensitive electronic systems and microprocessors control magnetic load. These systems are sensitive to various disturbances in the grid and their performance can easily disrupt. These disorders can cause huge losses that we mentioned above. Therefore investment and research is very important to improve power quality and today prevention from mentioned damage is very important. [1]

Electrical grids and consumers are designed based on sinusoidal voltage with constant amplitude and frequency. Any deviation of voltage or stream from this ideal state known as disturbances and it can cause dysfunction of the grid and consumers. Set of methods such as classifying, measuring and improving the disturbances studied in the section entitled "Power Quality".

One of the main characteristics of the studied systems is renewable energy sources, which at the same time in a few articles in this issue and also improving power quality discussed so in some of these articles in the absence of renewable energy sources, we can extract the positive points.

In 2008 Ferreira and et al. have developed a control strategy for shunt active filter (threephase four-wire) [2]. In this design for the filter is used an inverter tripod and two capacitors in parallel with the inverter. In [3] is presented a control strategy by using Tie Inverter models. Its aim is to improve power factor and to reduce the harmonic distortion without linear measurement. Jinwei and his colleagues presented control method of sliding discrete Fourier transform (SDFT) in 2010 [4]. Although most control methods for compensating harmonics act based on flow control (CCM) operation, but in this method is used from controlling the voltage (VCM).If distributed generation system operate in island mode, voltage control method and system provides conditions for the integration and it supports well of the voltage and frequency. In [5], they could significantly reduce the current THD using digital signal processing (DSP) and hysteretic control network. This system produces reference flows by sending signals of DC link voltage and voltage three-phase system to the DSP network cont four legs roller. Inverter pulses four legs produce by comparing the reference flows and flows of the network by hysteresis current controller. DC link voltage signal is given to the voltage regulator is to be multiplied in reference signal voltage and current signals of the reference system obtained. Finally, the reference signals will be compared with the mainstream system to produce pulses using hysteresis inverter controller. In 2012, Kannan and his colleagues presented a paper titled as photovoltaic-based on DSTATCOM [6]. This method is based on a model to increase PV and battery works connected to the converter. In fact, this converter, VSC tripod fed up with the Transformers star is a triangle (for fourth on the grid to trap Streaming wire) to provide suitable conditions for power quality. In reference [7] another method is provided to achieve sinusoidal current waveform synchronized to the unbalanced load compensation network. System structure is the same of DSP system with this exception that the error between the reference DC link voltage and the actual DC link voltage is given to controller neuro-fuzz instead of PI. The output of neuro-fuzzy controller adjusted more by renewable energy sources to reduce the injected flow.

The most important characteristic concerned in these methods, is improvement of the THD. Considering that in various articles different loads has been used, so the initial THD are different. Connecting renewable energy sources to DC link, the inverter will be completely supplied by injection or power absorption. Although in two controlled methods which is presented references [5, 7], simulations is used for DC link voltage instead of putting renewable energy sources models of oscillating signals DSP. In the proposed control system 
structure DSP method is used with this difference that instead of the traditional PI controller PI-Fuzzy controller used and the system has the advantages of fast response and also the proposed controller doesn't have the complexity of the calculation in neuro-fuzzy method [7] and using transforms of Streaming synchronous reference frame [6,7] .In the proposed system, it is used photovoltaic model, unlike [5,7] that they have used from DC link voltage signal and it has not been evaluated limitations of injected power.

\section{Modeling and systems analysis}

The overall system is composed of three main parts. In the right position of Figure 1we can see that the distribution grid (three-phase four-wire) by a transformer star (with neutral wire) is connected to the triangle or the distribution transformer to an infinite Shane. This collection has formed the grid system. The lower part of the figure, we can see a set of loads as threephase and single-phase. Loads used in this collection are just Nonlinear and unbalanced. We can see on the left side of Figure 1a set up renewable energy sources.Renewable energy sources are connected for energy exchange distribution network and inverter in parallel to the DC link. These three main parts are connected to each other at the PCC connection point.

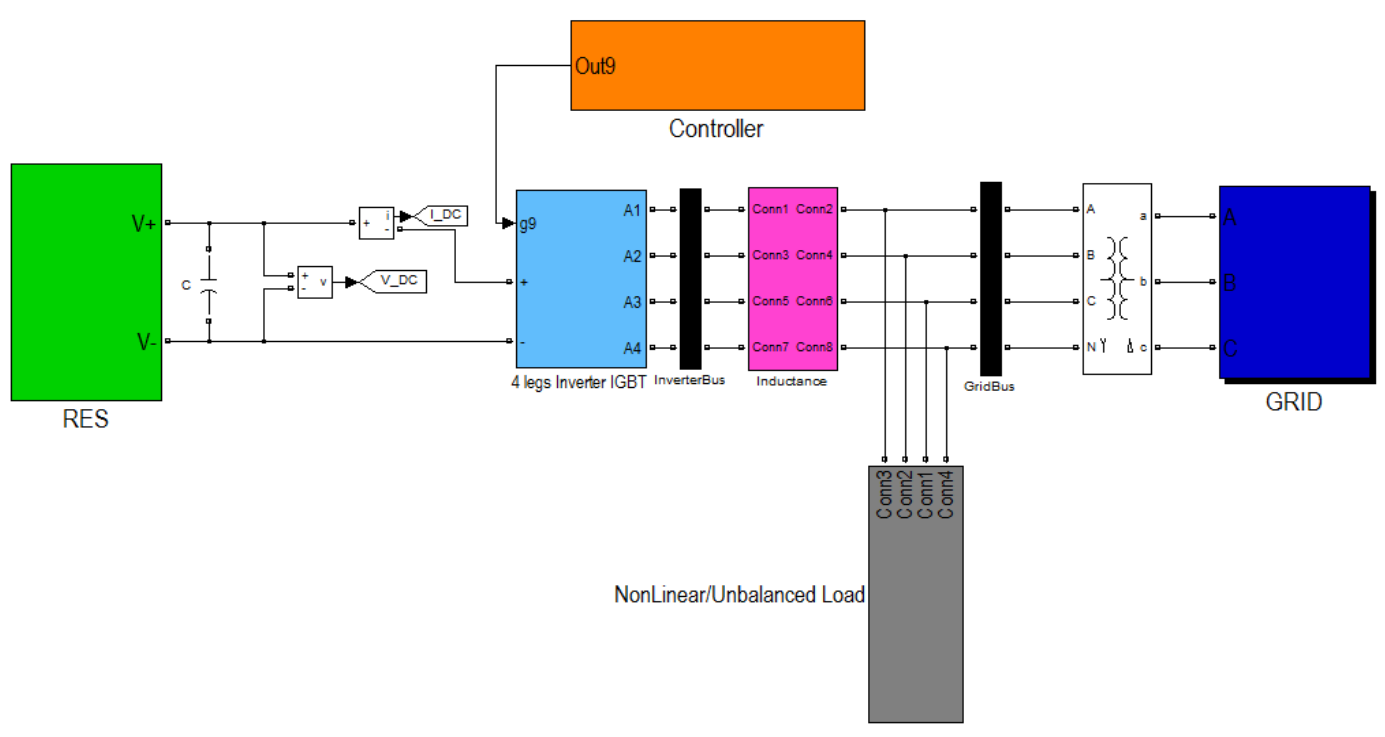

Fig. 1: The overall structure of the system

\section{PCC Hotspot}

PCC is the point that the subscriber or different loads in electrical networks connected to it. According to the standard IEEE-519, PCC is a point available for direct measurement of electrical consumers as well as connection to various equipments. In most cases, PCC refers to the point of measurement and easy access point. In general, to reduce harmonic distortion, PCC is considered as a measuring point or convenience point. In most cases, the flow through the PCC represents the sum of net flows associated with the charge component of linear and major components and distorted of non-linear loads. Distorted flow is usually less than the total amount of the principal component (combination of the two streams) in the PCC [8].

\section{Loads Connected to the PCC}


Increasing the electronic loads connected between phase and neutral, consumers of distribution network found that the dominant harmonic is third harmonic. This harmonic because of high neutral stream and neutral voltage to ground it basically shows its voltage distortion. Because transformers are not able to feed the main components of the stream to non-linear loads (effective current limiting transformers), so harmonic distortion can have a serious impact on distributed systems [9].

Electrical charges used in the system consists of a three-phase load ohmic-inductive nonlinear, one ohmic-inductive non-linear phase between the $\mathrm{C}$ phase and neutral conductors, and a single-phase ohmic-inductive load between phase $\mathrm{A}$ and neutral wire. Because all loads aren't three phase it certainly collection of loads becomes unbalanced. We can see an overview of loads connected to the four-wire network in Figure 2.

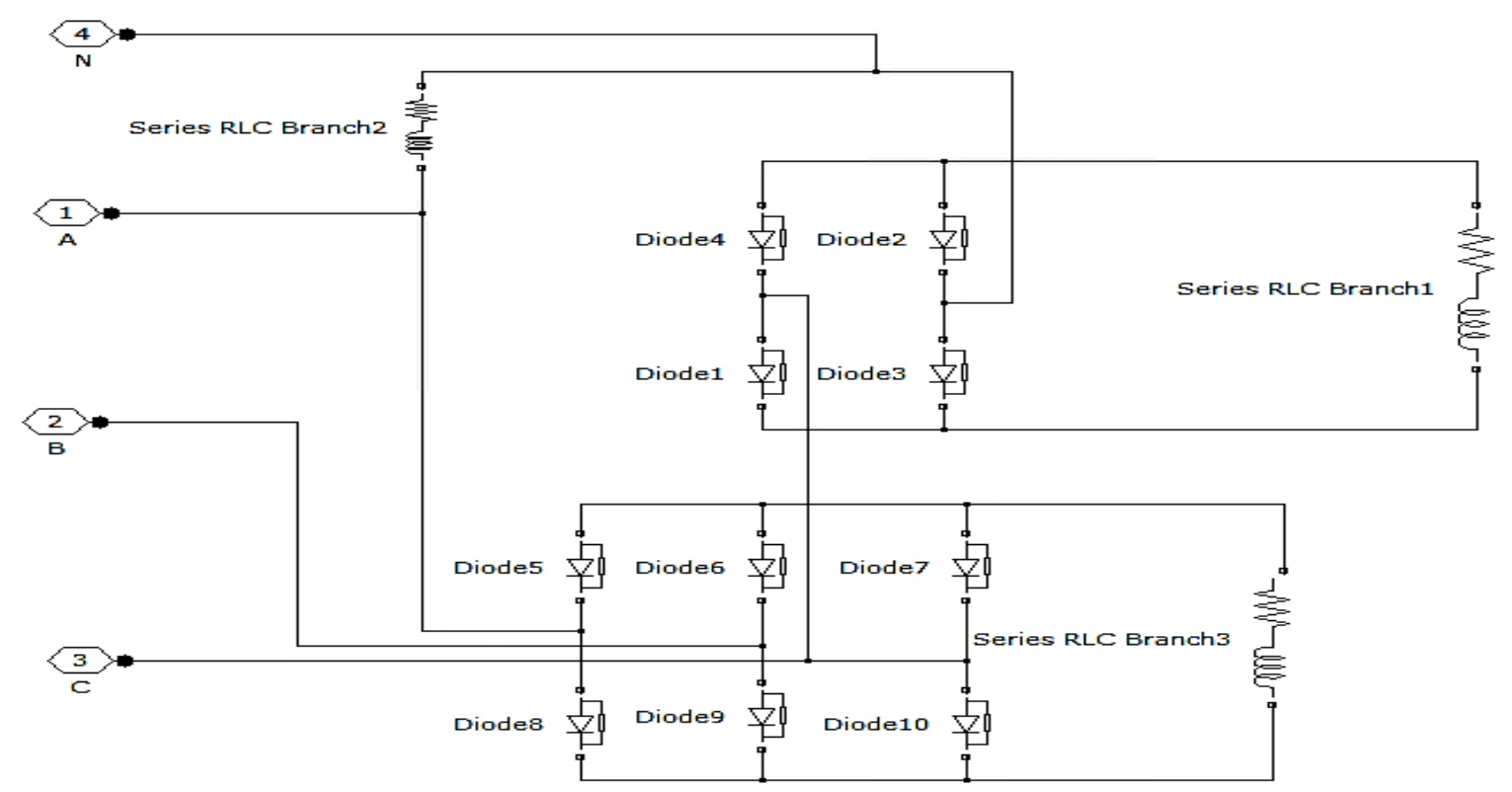

Fig.2: Electrical Loads Connected to the Grid

The above figure represents the nonlinearity of single phase diode key and three phases diode key and three-phase single-phase loads used in the circuit.

\section{Inverter Connected to Power Grid and DC Link}

All technologies of renewable energy sources that produce DC or AC power (different frequency from the network frequency); they should use a power electronic inverter to connect to the grid. Figure 3 shows the basic components of a grid connected to power inverter (according to the IEEE 929-2000 standards) [10]. In the left side of the figure has been entered direct current generation of power technology of DC or AC has been rectified and has entered to the inverter power. Using of this inverter systems in fuel cells is common in some micro turbines, photovoltaic systems and in some wind turbines [1]. 


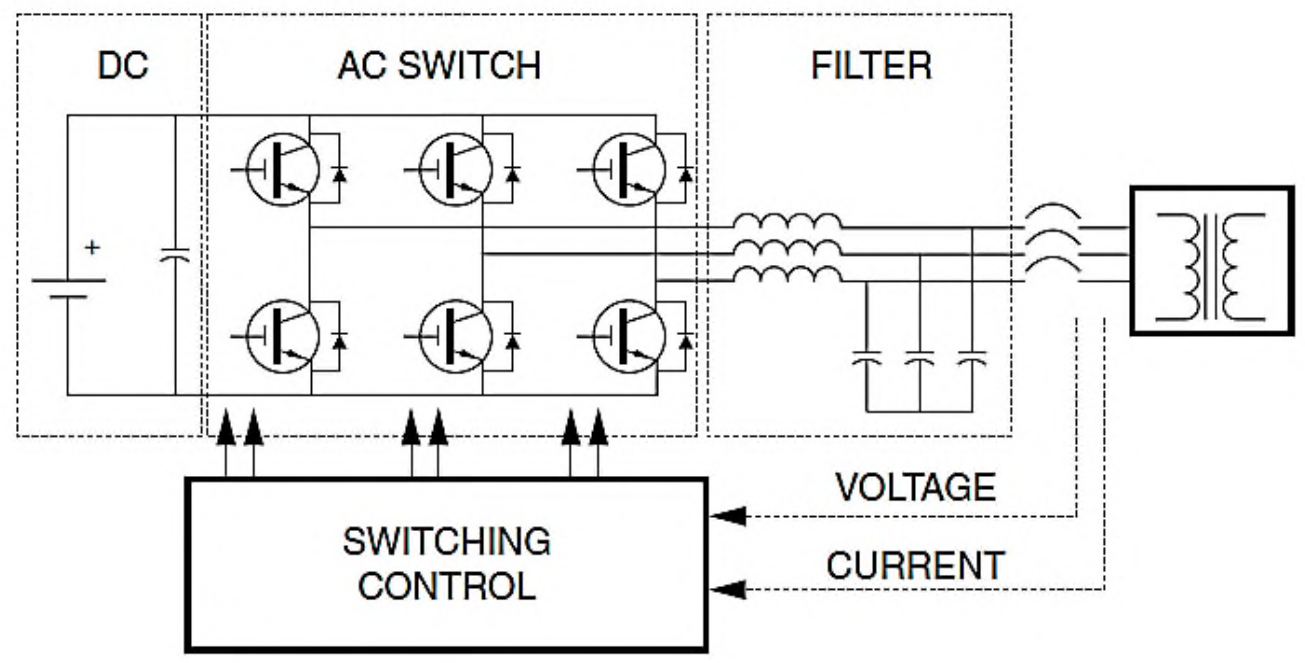

Fig.3: Outline of three-phase inverter [1]

It is usually used from the inverters to generate the sinusoidal current that follow the power grid voltage. As a result, the power exits from the inverter are one power coefficient. Different control strategies may be used for switching, but unity power factor strategy is simpler and more common. It also allows the complete transfer of the active power [1].Figure 4 shows the inverter used in the overall system, the inverter used has four legs. IGBT in the first-quarter, third-sixth, fifth, second and seventh-eighth respectively are used for phases $a, b$, $\mathrm{c}$ and the neutral wire. Because the inverter is connected to the PCC in four-wire distribution systems therefore the fourth grade is embedded to flow the neutral wire current to DC link,

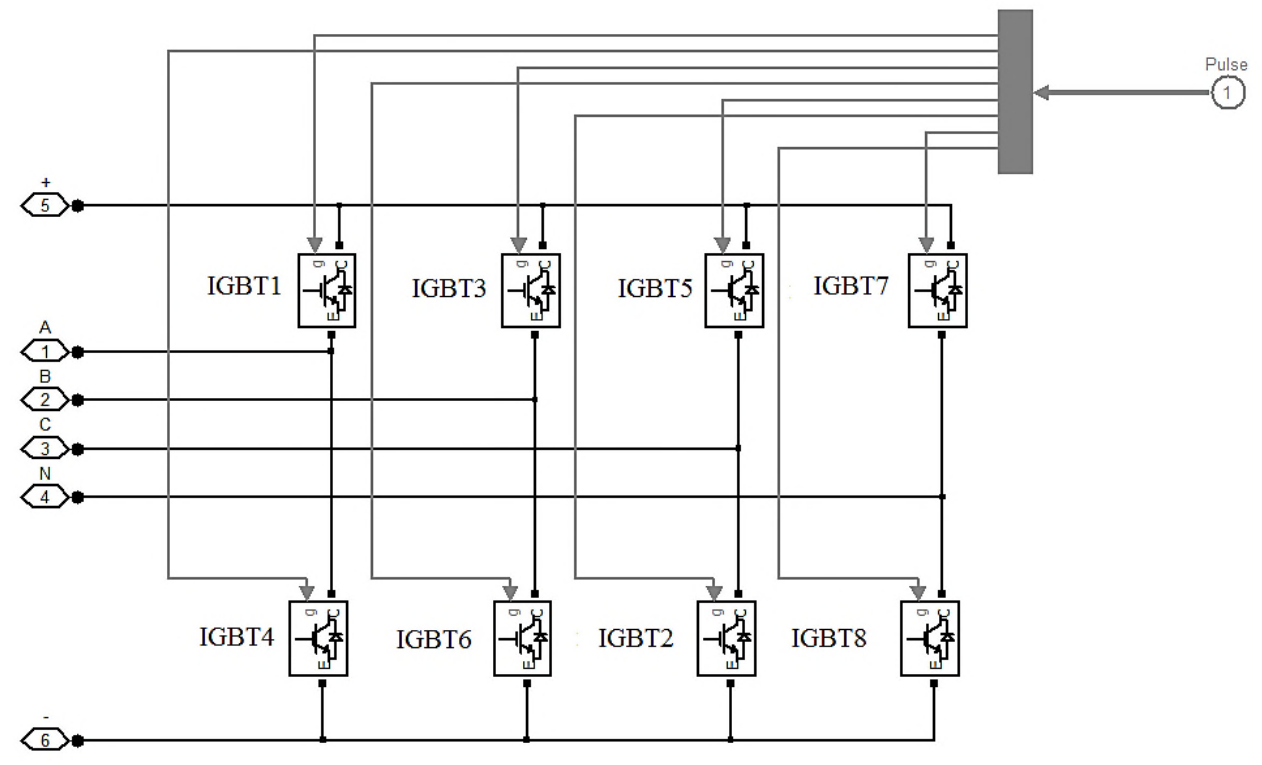

Fig.4: The 4 base inverter used in the general system

\section{Switching Strategy Pulse Controller}

The most important thing about these inverters is how to control and switch them. Yet Different methods have been described in the inverter control. The majority of control strategies are designed based on the transformation of DC link voltage and voltage pure sine 
wave at the output of inverters. In the plan proposed system as shown in Figure 1, the PCC plays the role of a node and Kirchhoff's current low is true for currents distribution network, load and inverter. Inverter controller is switching action takes place in order to compensate for the load at PCC.

Since current waveform of nonlinear loads and unbalanced is not a sinusoidal perfect, So the impact of these loads on the current of grid causes the component harmonic on the lower side appear in the current waveform on the grid. As a result inverter injects non-sinusoidal current to the PCC point to be gathered with current load and finally we will have a sinusoidal current distribution system in the grid. The overall structure of the inverter controller is shown in Figure 5. The controller is composed of several different parts, the more parts of PLL, PIFuzzy and control Hysteresis will be described separately.

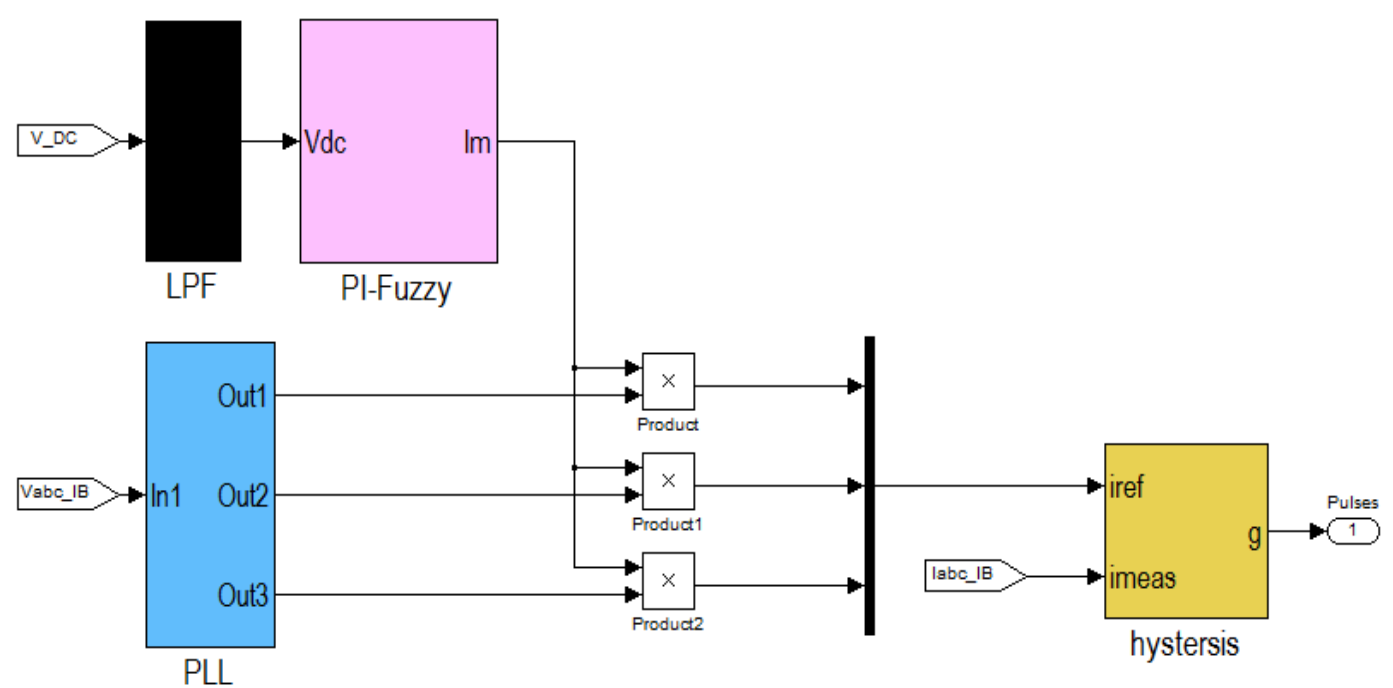

Fig.5: The block structure of the inverter controller

\section{The Version of Phase-Locked Loop (PLL)}

As mentioned in the first chapter, the controller works to produce the reference signal for comparison with net power flows in hysteresis controller. Therefore, it is necessary to follow factor reference current signals, power grid voltage waveform to achieve unity power. In this regard, entering the power grid voltage to a locked loop phase, the power grid voltage angle $(\theta)$ is derived and according to equation (1), (2) and (3), these angle units are used for the production of three-phase voltages.

$$
\begin{aligned}
& U_{a}=\operatorname{Sin}(\theta) \\
& U_{b}=\operatorname{Sin}\left(\theta-\frac{2 \pi}{3}\right) \\
& U_{c}=\operatorname{Sin}\left(\theta+\frac{2 \pi}{3}\right)
\end{aligned}
$$

Voltage signals generated have phase difference 120 degrees relative to each other and are shown in Figure 6 [5]. 


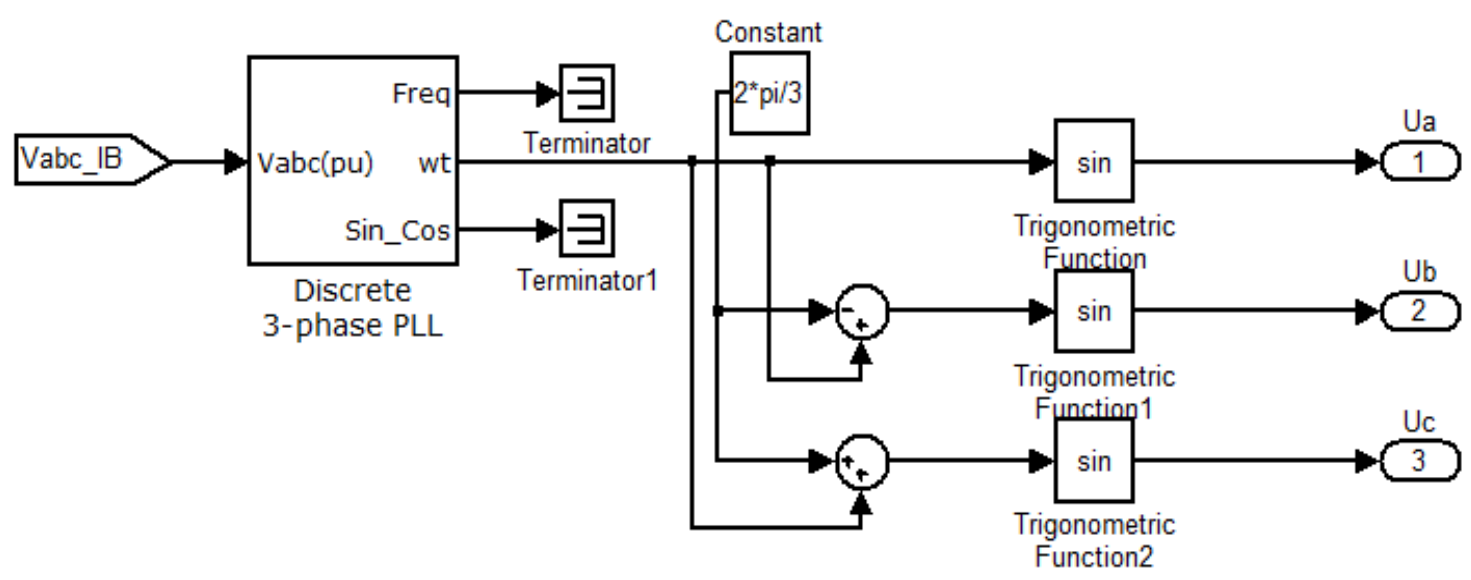

Fig.6: production of Unit voltage signals by PLL

\section{PI-Fuzzy Controller}

The main part of controlling in figure 5 consists of how the reference signal form $I_{m}$ ) produces. After measuring DC link voltage, voltage signal is switching from Low Pass Filter will be passed due to fluctuations removing of switching. A signal that passes through the filter $\left(V_{D C}\right)$, will compare to stabilize the DC link voltage to a DC voltage reference $V_{D C}^{*}$ ). DC link voltage reference and DC voltage difference according to equation (4) as voltage error $\left(V_{D C e r r}\right)$ to a fuzzy logic controller is applied for proportional and integral gains generated discrete PI controller.

$V_{D C \operatorname{cor}(n)}=V_{D C}^{*}-V_{D C(n)}$

$$
I_{m(n)}=I_{m(n-1)}+K_{P V_{D C m}}\left(V_{D \operatorname{Corr}(n)}-V_{D \operatorname{Corr}(n-1)}\right)+K_{I V_{D C m}} V_{D \operatorname{Cerr}(n)}
$$

PI discrete controller output in-the $\mathrm{n}$ time, according to equation (5) produces the reference signal $\left(I_{m}\right)$ [5]. To extract the optimum amounts of PI controller interest by fuzzy logical software controller, it is used the Hybrid Control. The proposed controller structure is shown in Figure 7.

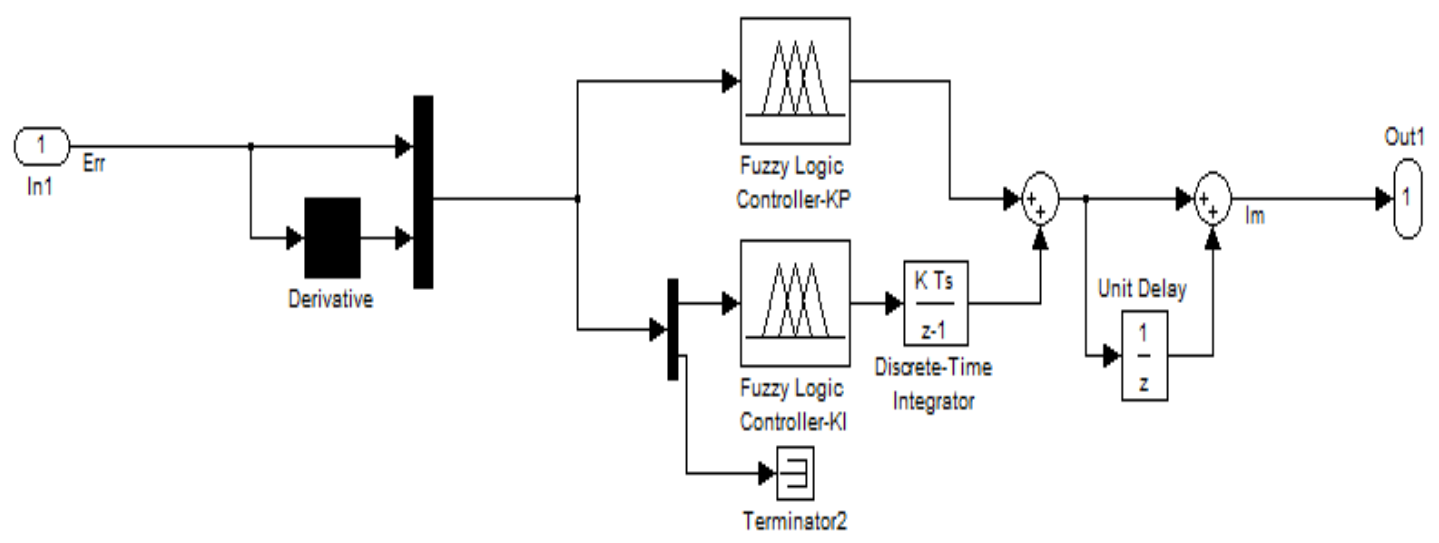

Fig.7: PI-Fuzzy controlle 


\section{The Hybrid Control}

We can divide controllers basically into two general groups; software control and hardware control. Hardware Controls such as PID control, optimal control, robust control, adaptive control, sliding mode control, etc. are very common in the simulation theory and practical designs. Today, with development in programming science and exchange of information technology, it is used software manipulators like fuzzy control and neural networks control [11].

In the hybrid control strategy we can control both software and hardware control or used a combination of the controller.In this case, control will be a combination of different features that a controller alone is without them. The proposal for inverter control system it is used from PI-Fuzzy hybrid controller.

We know well that PI controller for simple control structure, easy to design and its low price is very common and it is used widely in industry [12]. However, the controller proportionalintegral in non-linear control elements have completely uncertain function. On the other side it is used of the fuzzy logic controller due to high flexibility and natural performance in the most and uncertain nonlinear systems [13].

\section{Waste controller}

Waste or modulation of bandwidth Bang-Bang on the basis of an error between the actual measured data and reference signals, directly is switching for each of the foundations of the inverter switching. For example, in the first grade:

If $I_{a}<\left(I_{a}^{*}-\varepsilon\right)$ is high key in the first base (a phase) in the case of off is $\left(P_{1}=0\right.$ ), and down key in on $\left(P_{4}=1\right)$. However if $I_{a}>\left(I_{a}^{*}-\varepsilon\right)$, high key first base (phase a) in the case of on will be $\left(P_{1}=1\right)$ and down key on the off $\left(P_{4}=0\right)$. For the three remaining terms the conditions will be as the above, that we can mentioneas the controller waste of bandwidth as their name. Figure 8 shows the above conditions for first base.

Waste controller function is easily a hysteresis mode operational amplifier in waste mode, so it does controller and model task in a single unit. Waste strategy often used in analog circuits, they simply be practical because of the need for quick performance comparison.

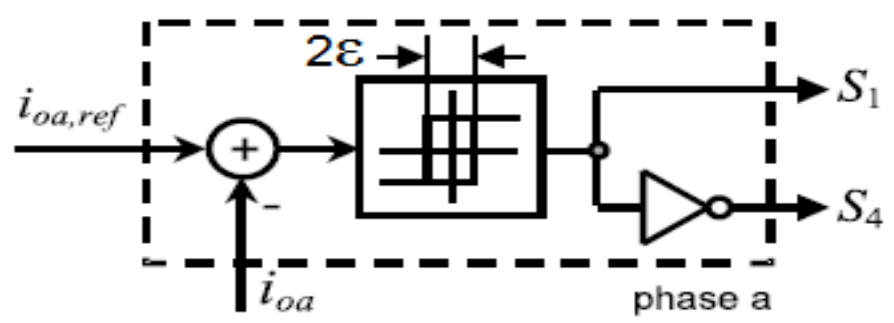

Fig.8: Waste and conditions of domain bond controller

When the high-frequency harmonics disrupt the flow measured, the results of instantly fires fast switching deal with problems. We can fix this problem by raising bond of each residual block or we can resolve by filtering the flow measured. In residual control for a given output sample, the leg of the inverter must be fully open or fully closed. As a result lowest differentiable bandwidth established by the sampling period foundation. Thus, for a very high sampling frequency to accelerate the response, it is required intersect waveforms with high precision and no production of significant harmonic [14].Because waste controlling can independently control the two lines of the network at any moment, it is only suitable for three- 
phase loads that have $4^{\text {th }}$ wired [15].As you see in Figure 9, the switching in controller isn't not periodic.

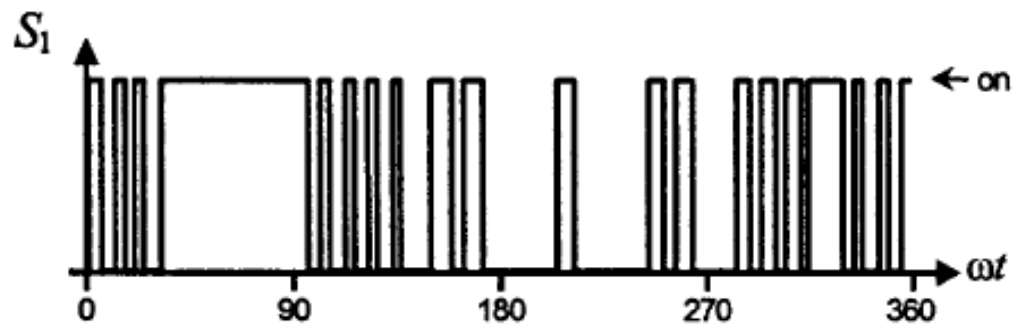

Fig.9: Switching of waste controller in the first grade

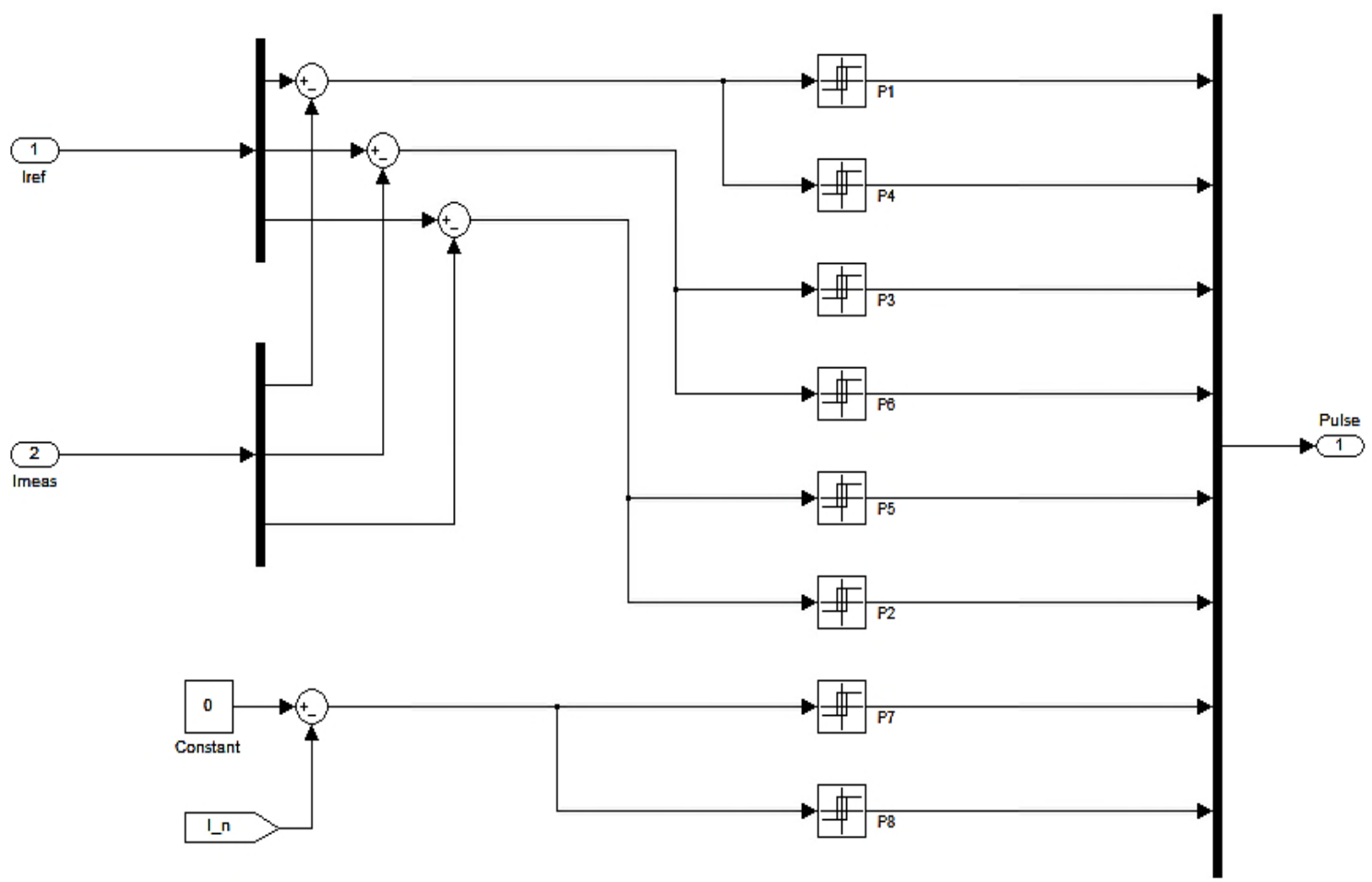

Fig.10: Production of 8 pulses by waste controller

In fact, from the eight-controlling waste used for comparison between reference currents and measurement currents by the network and the production of eight required pulse inverter. After reference flows were calculated in the previous section, by comparing reference currents and streams flow measurement of the network, signals of current error obtain on the relationships of (6 to 9).

$$
\begin{gathered}
I_{\text {anr }}=I_{a}^{*}-I_{a} \\
I_{\text {barm }}=I_{b}^{*}-I_{b} \\
I_{\text {aerm }}=I_{c}^{*}-I_{g} \\
I_{\text {norm }}=I_{n}^{*}-I_{n}
\end{gathered}
$$

Residual current controller pulses $\left(\boldsymbol{P}_{1}-\boldsymbol{P}_{\mathrm{g}}\right)$ required inverter connected to the network is prepared for switching as shows in Figure 10. We can connect 4 inverters to the grid by using the equations of state space (10 - 14) model [16].

$$
\frac{d l_{\text {inva }}}{d t}=\frac{\left(V_{\text {mwa }}-V_{a}\right)}{L_{\text {sh }}}
$$




$$
\begin{aligned}
& \frac{d I_{m w b}}{d t}=\frac{\left(V_{m w b}-V_{b}\right)}{L_{s h}} \\
& \frac{d I_{\text {inwe }}}{d t}=\frac{\left(V_{\text {inwe }}-V_{s h}\right)}{L_{\text {sh }}} \\
& \frac{d I_{\text {inw }}}{d t}=\frac{\left(V_{\text {inn }}-V_{n h}\right)}{L_{s h}} \\
& \frac{d V_{D C}}{d t}=\frac{\left(E_{\text {invad }}+I_{\text {invad }}+I_{\text {hnvad }}+I_{\text {invad }}\right)}{C_{D C}}
\end{aligned}
$$

In the above equations $V_{\text {imva }} \cdot V_{\text {imb }} \cdot V_{\text {imw }}$ and $V_{\text {imm }}$ represents the inverter output voltages due to switching.

As you see in equations (10 - 14), the task of inductances of shunt (as it is clear in Figure 1), is the integration of the inverter output voltages. Switching voltage by inverter foundations, square pulse output voltages will achieve. As a result by integration of these pulses, 4 inverter foundations currents take sinusoidal mode.

\section{Modules, Panels and PV Array}

In this study it is used of an array for solar cells as renewable energy sources in order to study its effects on power quality at the point of PCC. To obtain energy and a higher voltage from solar cells it is required to make them in series and parallel to form a module. If it needs more voltage and current, they make modules as series and parallel together to form the panel. Similarly, as shown in Figure 11, to obtain more energy, it will use solar cells array [17].

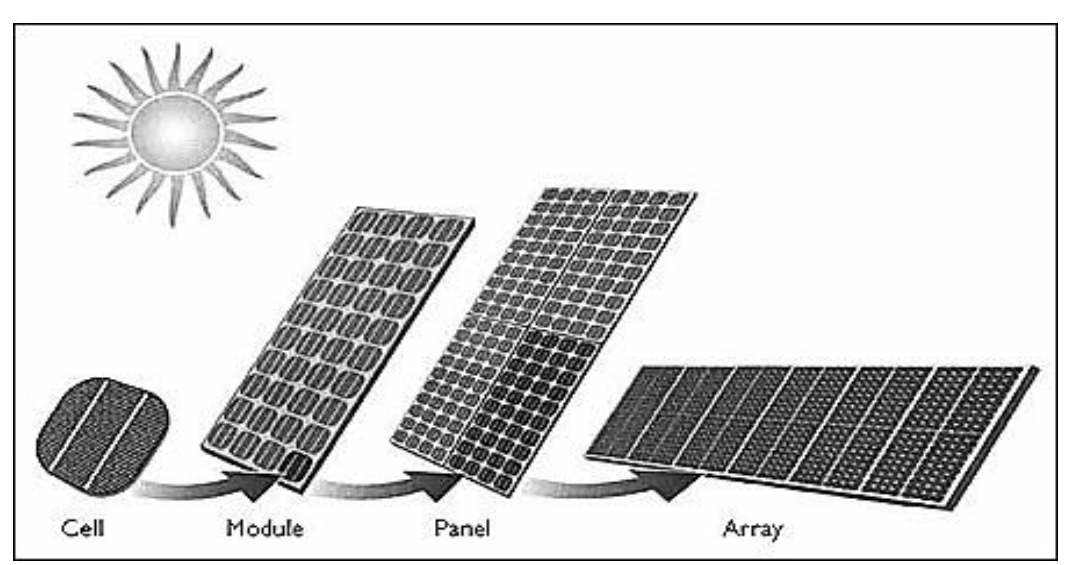

Fig.11: Schematic view of cells, modules, panels and solar array

\section{Maximum Power Point Tracker (MPPT)}

When solar array exposed to the sun and feeds load, necessarily loading point does not comply on the maximum power point. Considering the high price of solar array, it is essential that the operating point be always at the maximum power point of the array to be absorbed the maximum power point of the array. MPPT system to regulate the flow array or its voltage leads the task point to the MPP [15]. Common methods such as Perturbation, observation method ( $\mathrm{P} \& \mathrm{O}$ ) and incremental conductance method (IC) has been presented in numerous articles in order to achieve this goal [18]. 

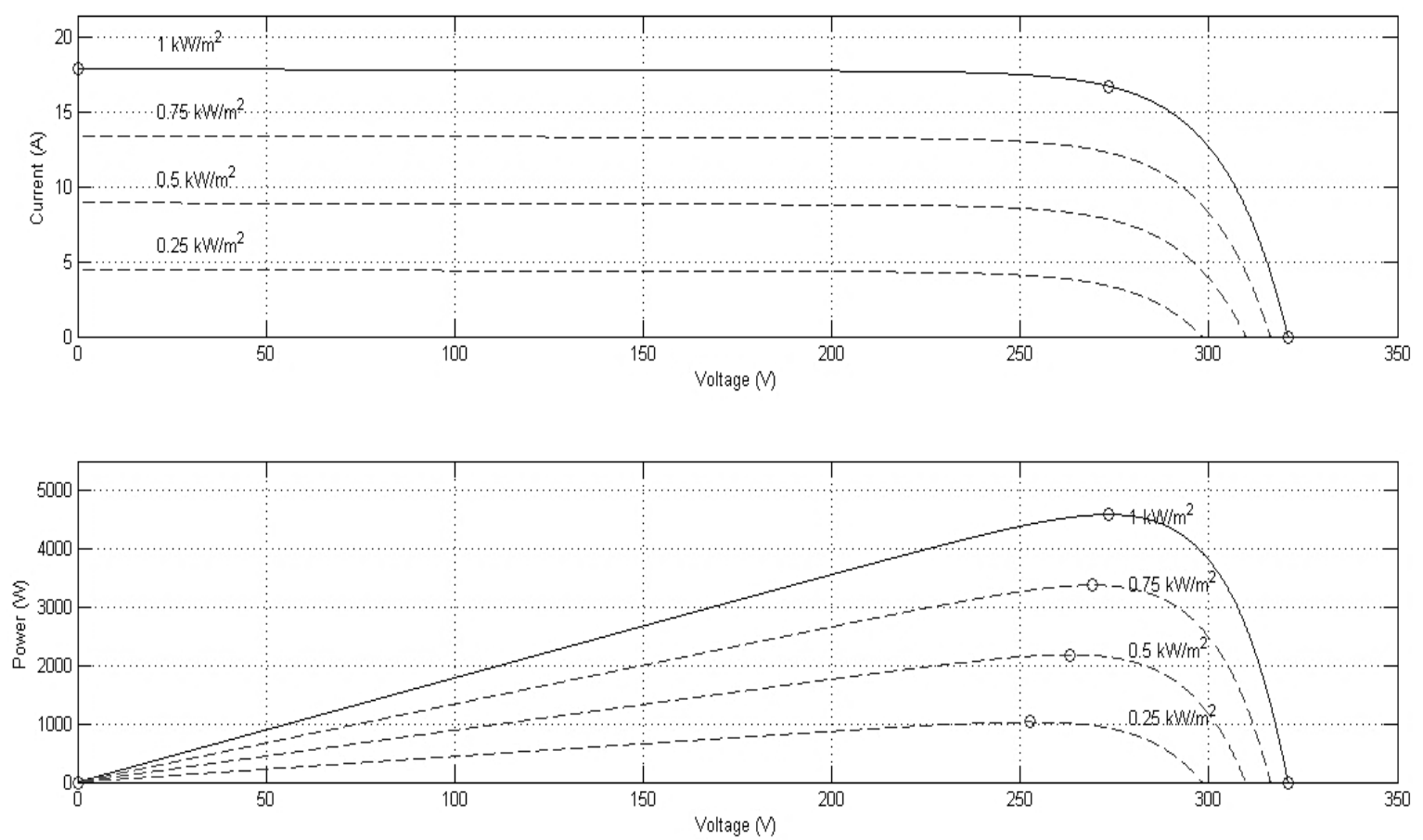

Fig.12: Changes in Radiation Intensity (voltage-current curve and voltage-power curve)

Points identified in Figure 12 show the maximum power generated by array under variable radiation intensity. The slope of the curve voltage-power at the point of MPP is zero $\frac{d P}{d V}=0$ ), slope on the right of specified point is negative $\frac{d P}{d V}<0$ ) and on the left will be positive $\left(\frac{d P}{d V}>0\right)$. According to the following equation for the ratio of voltage changes to current, it will be:

$$
\frac{d P}{d V}=\frac{d(U V)}{d V}=I+V \frac{d I}{d V} \cong I+V \frac{\Delta I}{\Delta V}
$$

On the point

On the left point

On the right point

$\begin{array}{ll}\text { MPP } & \frac{\Delta I}{\Delta V}=\frac{-I}{V} \\ \text { MPP } & \frac{\Delta I}{\Delta V}>\frac{-I}{V} \\ \text { MPP } & \frac{\Delta I}{\Delta V}<\frac{-l}{V}\end{array}$

By increasing the output controller, fuzzy logic of reference current is increased, thereby high inverter IGBT will be in the ON state, which means that (due to the constant voltage) current from renewable energy sources (photovoltaic array) transferred to the PCC and by reducing the controller output, the opposite will occur. Fuzzy logic controller input includes variations in link voltage DC (photovoltaic array voltage), so by taking control of the same membership functions for input and output fuzzy logic in equation correctness (16) will be realized.

\section{Analysis of Current Harmonics}

With respect to the earlier part about analysis and overall modeling of system as well as the proposed control strategy, in this chapter of the study we will discuss about simulation and numerical results to prove the efficiency of the control system.

Current harmonic analysis of the network will be investigated. Specifications of used loads in the PCC point and also the amount of fixed parameters listed in Table 1. 
Bulletin de la Société royale des Sciences de Liège, Vol. 85, 2016, p. 61 - 78

Table1: System Parameters

\begin{tabular}{|c|c|}
\hline Values & Parameters \\
\hline $100 \mathrm{~V}, 60 \mathrm{~Hz}$ & Network voltage (effective value) \\
\hline $\begin{array}{l}\text { With the } 16 / 66-\mathrm{ohm} \text { resistor and inductor } \\
3.33 \mathrm{~mm} \text { Henry }\end{array}$ & Three-phase non-linear loads \\
\hline $\begin{array}{l}\text { With the } 66 / 26 \text {-ohm resistor and inductor } \\
3.33 \mathrm{~mm} \text { Henry }\end{array}$ & Time linear phase (between phase a and $n$ ) \\
\hline $\begin{array}{l}\text { With the } 16 / 66 \text {-ohm resistor and inductor } \\
3.33 \mathrm{~mm} \text { Henry }\end{array}$ & $\begin{array}{l}\text { Time non-linear phase (between phase } \mathrm{c} \\
\text { (and } \mathrm{n}\end{array}$ \\
\hline $\begin{array}{l}3000 \text { micro-farads with a reference voltage } \\
\text { of } 250 \mathrm{~V}\end{array}$ & DC link capacitor \\
\hline 2 mm Henry & Inductive filter inductor \\
\hline
\end{tabular}

It should be mentioned that all the simulations and studies in this paper is done by the MATLAB software (Simulink and Fuzzy) and 7.12 (R2011a) versions.

As mentioned in the previous chapter, the three-phase inverter controller before applying the network to bear the load connected to the PCC. In Figure 13 we see that in 7/0 second inverter controller enters into the circuit. Changes in net current waveform are obvious after equalization act.

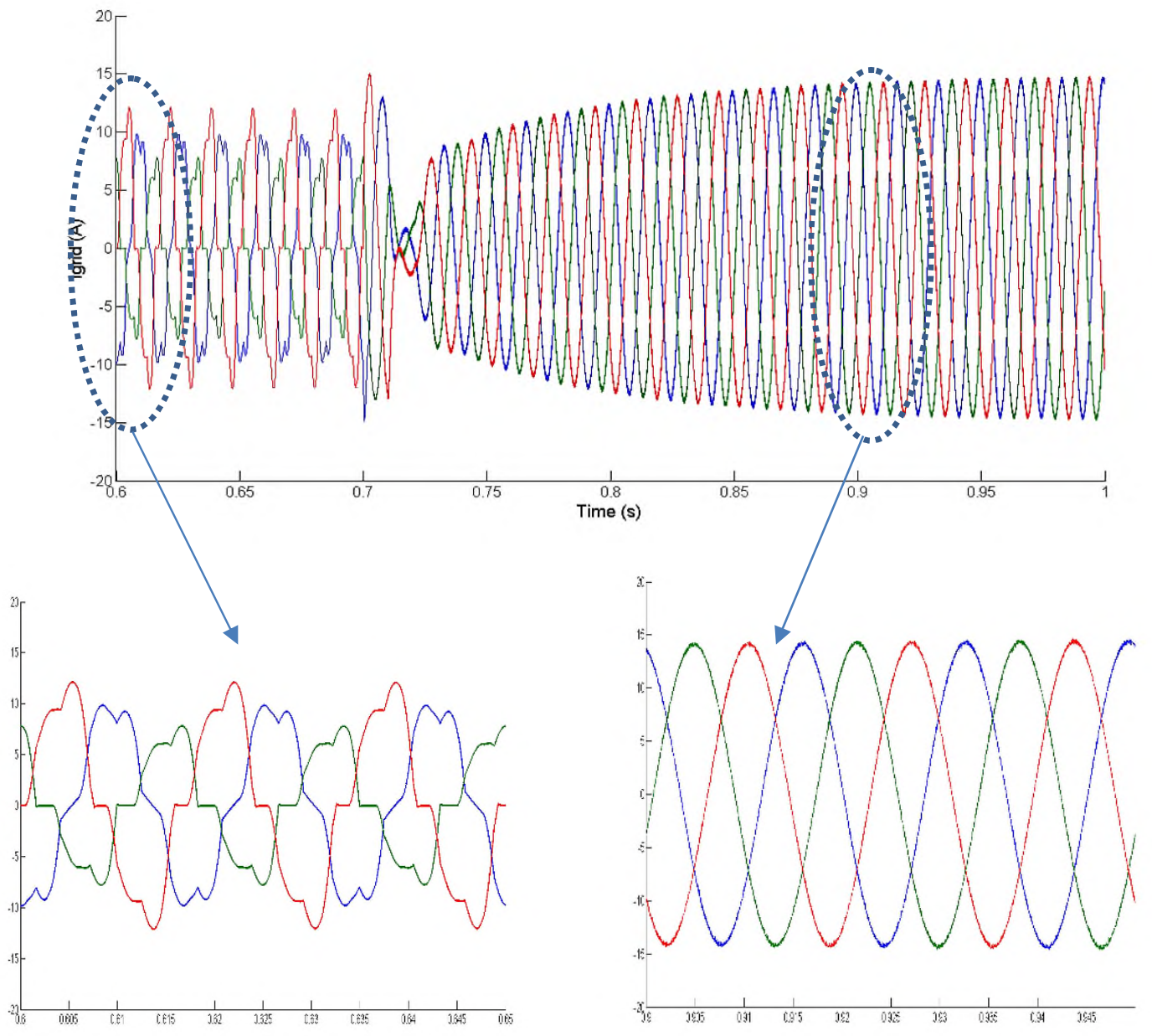

Fig.13: Net current waveforms shape before and after the controller 
As you see in Figure 14, grid voltage (is used as PLL signal reference) remains in a $\mathrm{Pu}$ constant. Prior to the compensation, network current equals with the load current. After the current controller network performance, it will follow the variation of inverter output current and load current.

$I_{\text {grid }}=I_{\text {inv }}-I_{\text {load }}$

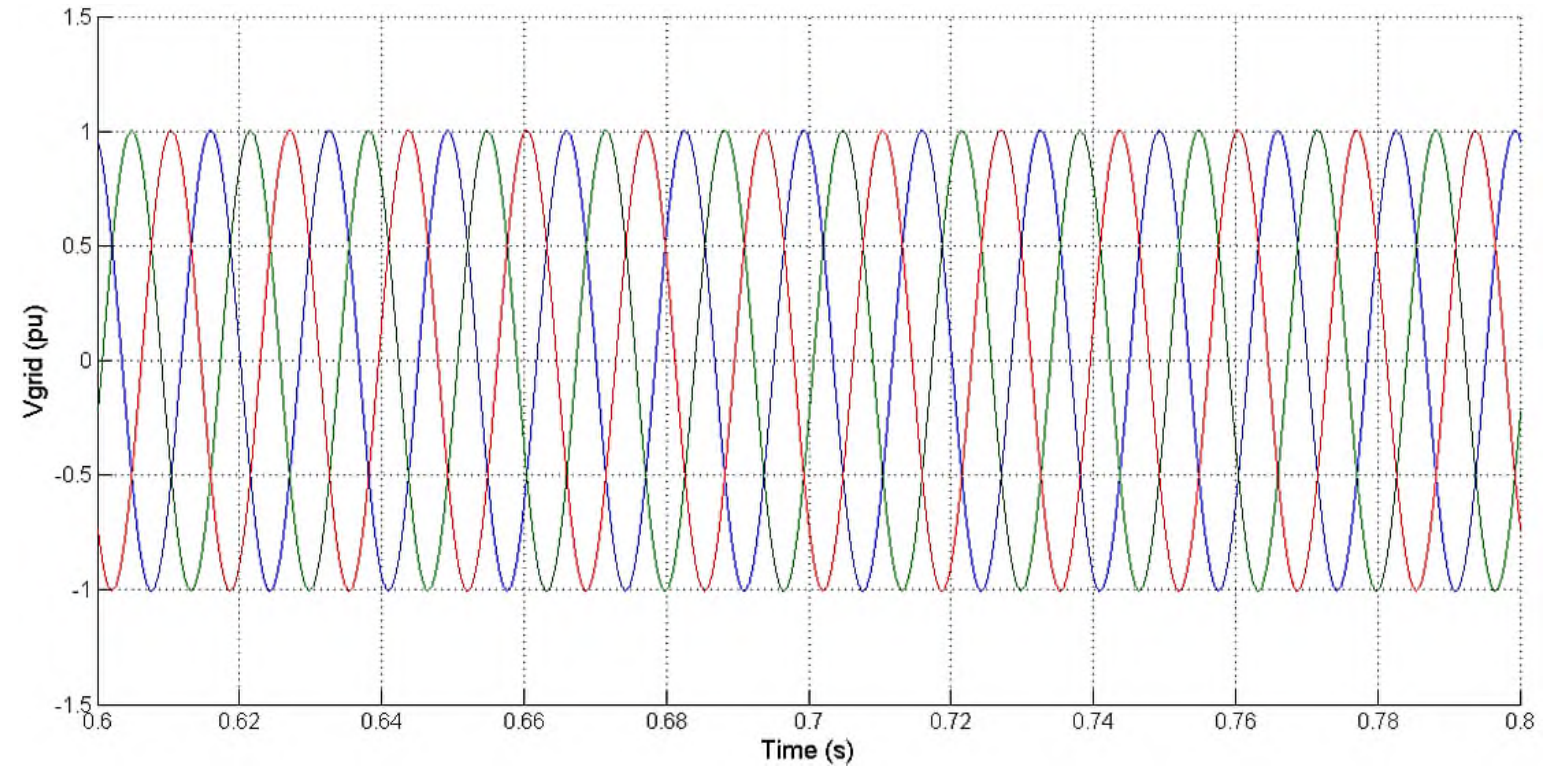

Fig.14: The network voltage

Inverter output current equals to zero before switching. After compensation, according to inverter current waveforms and load, we can see that the differences between these two trends are complementary and they provide a sinusoidal current network. In Figures 15 - 17, respectively inverter currents, it shows load and grid after the controller acts.

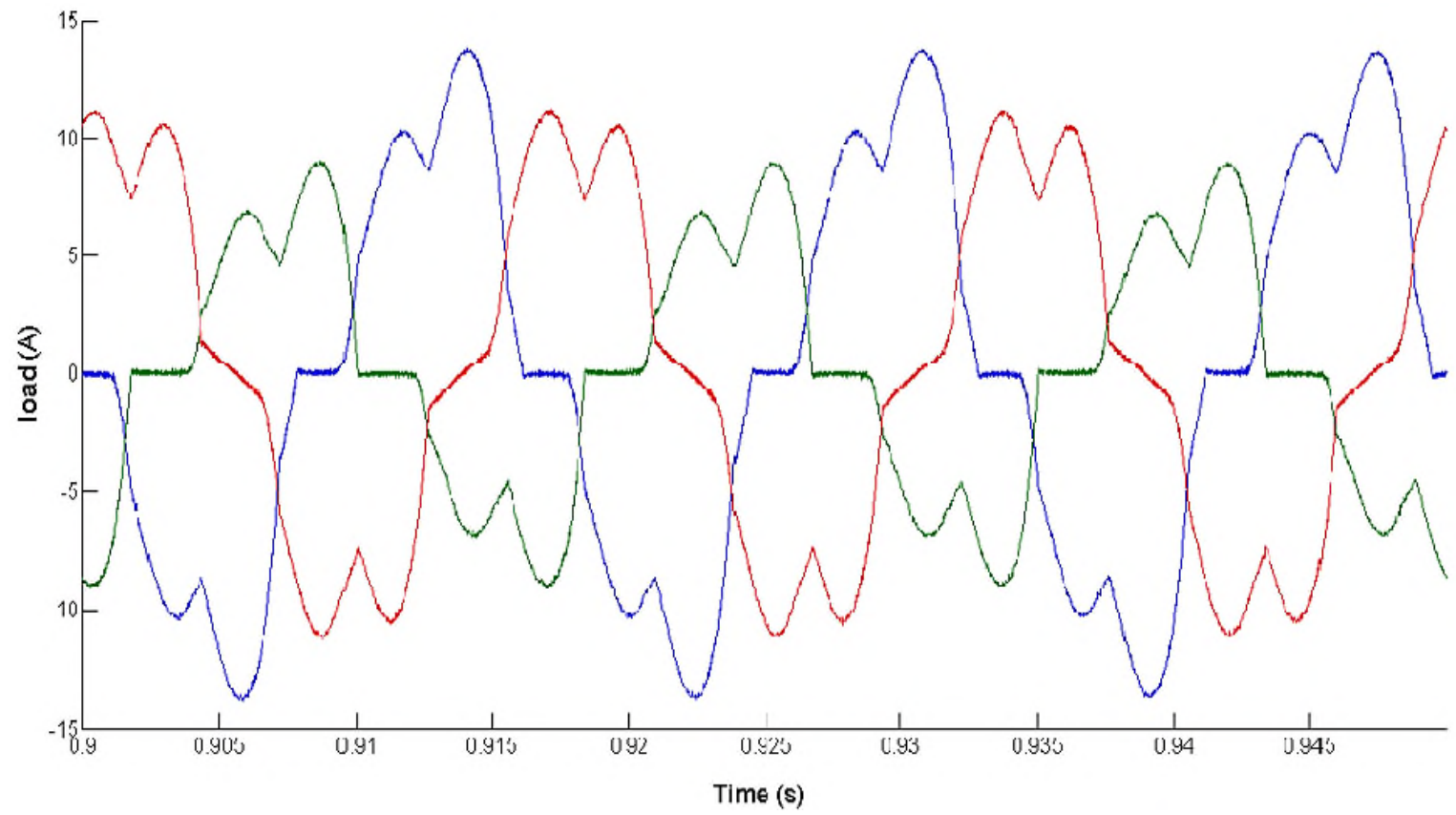

Fig.15: Inverter Current after Applying the Controller 


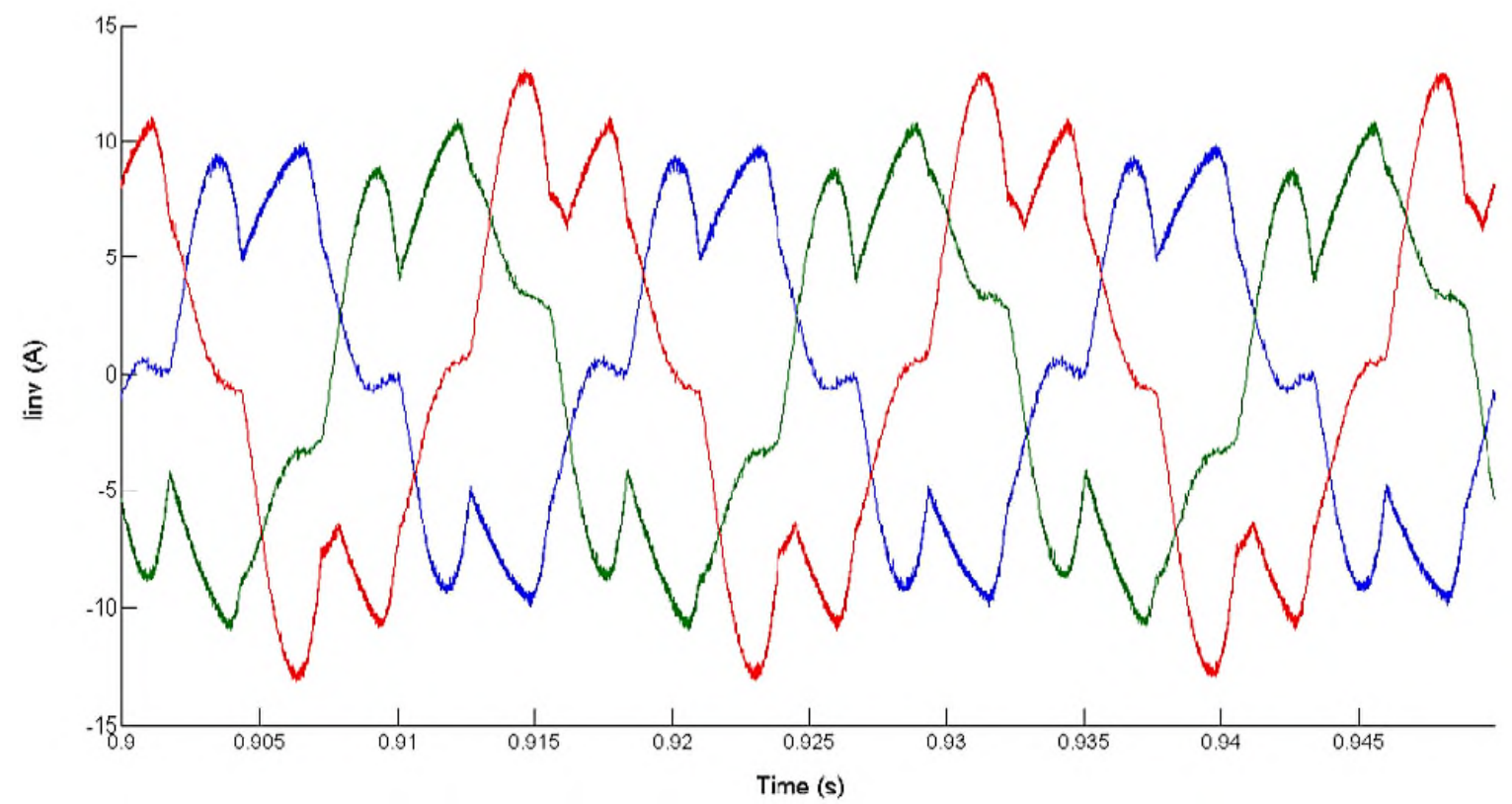

Fig.16: Load Current after the Applying the Controller

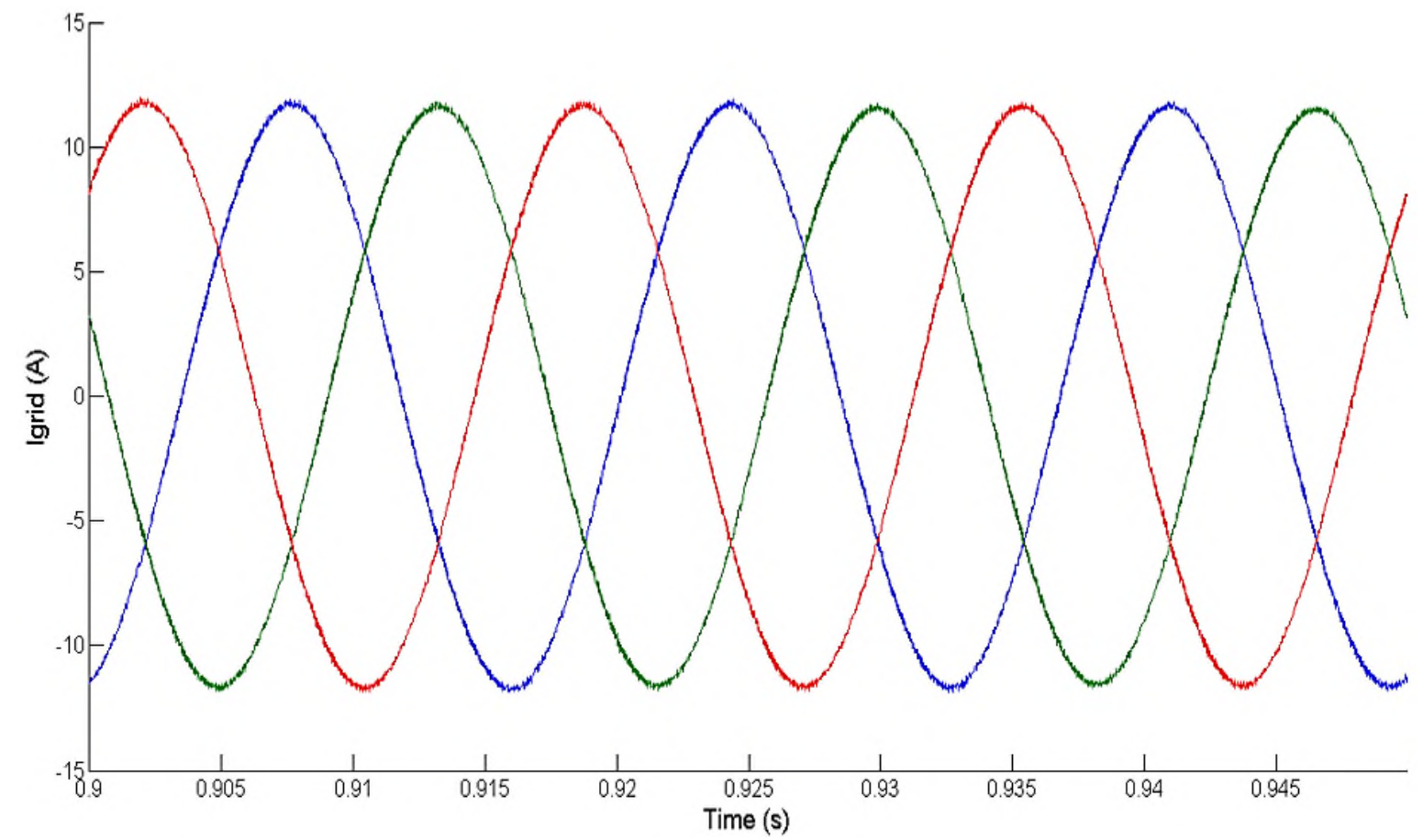

Fig.17: The Grid Stream after Applying the Controller

If in the time of one second, energy solar arrays reduce to zero, Net current waveform subsequently reversed and energy from the Grid loaded. With this difference that the output current of infinite Shane has been compensated by the inverter and the DC link. Figure 18 illustrates this issue. Based on Figure 18, after the controller enters to the circuit, current waveform of sine grid has become from nonlinear and unbalanced to complete sine mode. Total harmonic distortion is obtained using Equation 18. 


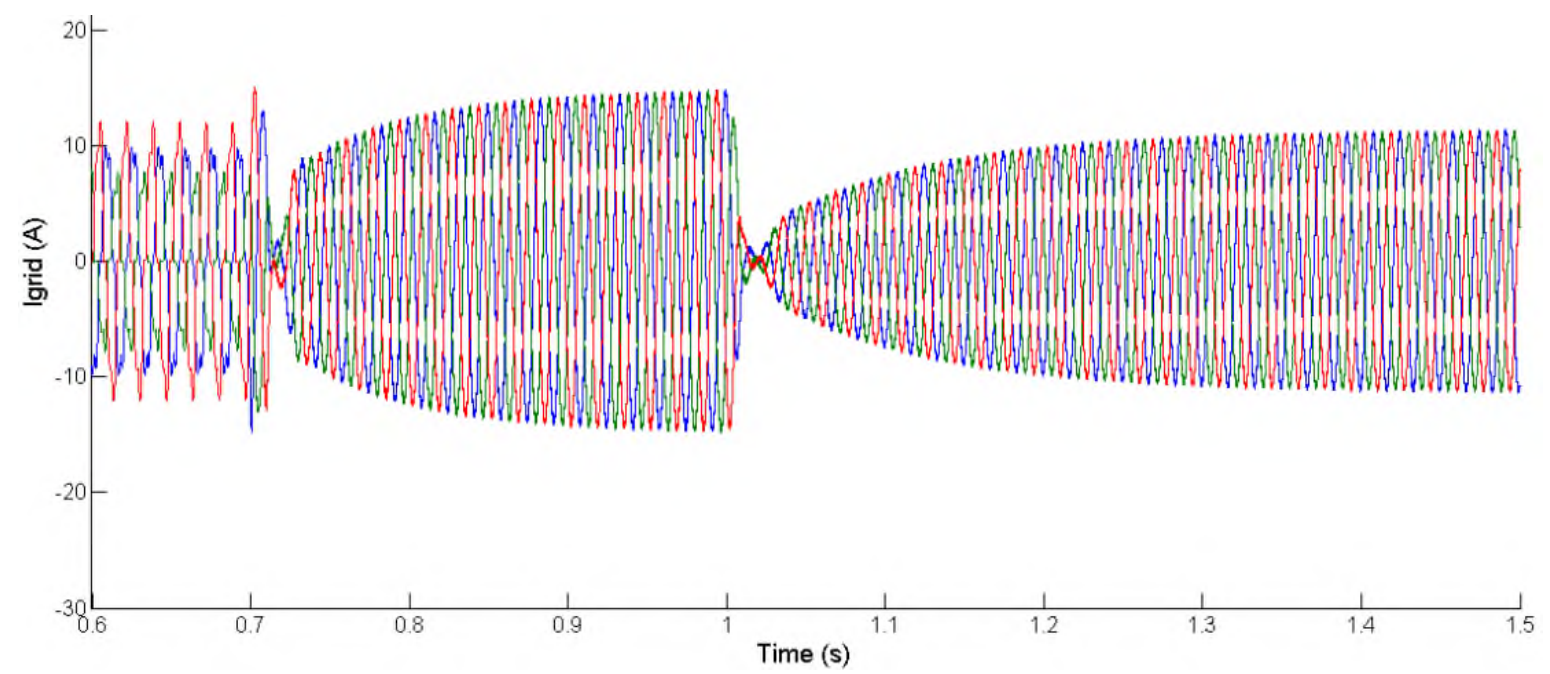

Fig.18: The three-phase of current network

$$
T H D_{2}=\frac{\sqrt{\sum_{h=2}^{\infty} I_{h}^{2}}}{\Gamma_{1}}
$$

This relationship suggests that the effective value of the harmonic signals component of the current to the effective amount represents the total harmonic distortion [19]. Calculation of the total current harmonic distortion for the network is shown in Figure 19 for one phase (before and after the application handler). Table 2, the amount of compensation THD before and after compensation indicates by the presence of RES and without presence of RES.

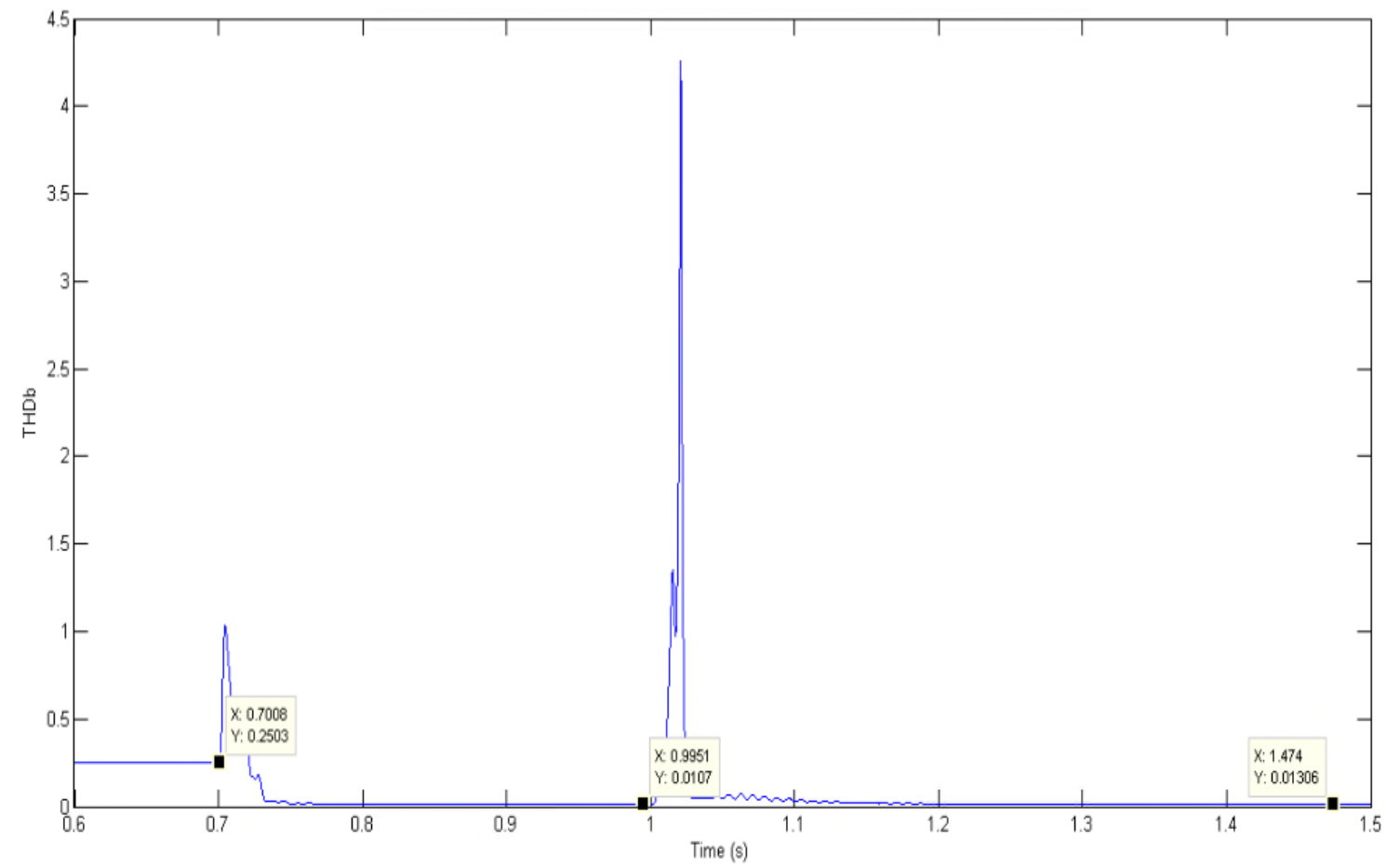

Fig.19: the total Harmonic Distortion 
Table 2: THD of Grid Stream

\begin{tabular}{|c|c|c|c|}
$\begin{array}{c}\text { network } \\
\text { stream }\end{array}$ & $\begin{array}{c}\text { THD percent } \\
\text { before } \\
\text { compensation }\end{array}$ & $\begin{array}{c}\text { THD percent after } \\
\text { compensation (in the } \\
\text { presence of RES) }\end{array}$ & $\begin{array}{c}\text { THD percent after } \\
\text { compensation (without } \\
\text { RES) }\end{array}$ \\
\hline a phase & 17 & 1.07 & 1.25 \\
\hline b phase & 25.03 & 1.07 & 1.3 \\
\hline c phase & 21.34 & 1.03 & 1.3 \\
\hline
\end{tabular}

The simulation results show that the controller, not only acts pretty well as an active power filter, but by applying energy by solar arrays, improving of stream current harmonics has been even better. Based on the standard of IEEE 519-1992, the extent permitted of total harmonic distortion is obtained less than 5\%. Relatively the total harmonic distortion to 86/94 compensation percent compared to the previous works has been improved much more.

\section{Conclusion}

In this study, a new controller strategy for grid-connected inverter control to improve power quality was presented at the PCC point distribution system of three-phase four-wire. By providing an introduction of power quality issues and renewable energy sources, several performances of control strategy conducted and completed review of system structure, control strategy and also outlines of photovoltaic arrays was performed as renewable energy sources. As a result, it was shown that inverter of renewable energy sources besides doing its normal work (power transmission) it was also effective to improve power quality. Inverter connected to the grid by controls, it can do the same performance as the active filter parallel power. In this method, the grid current harmonics that created due to the presence of non-linear and unbalanced loads in the PCC point, they were compensated well; so that the grid current after compensation was achieved fully balanced in three-phase and also sinusoidal course. When Production capacity by photovoltaic array is higher than the load, inverter connected to the network and the control strategy not only provides the time value of active and reactive power (with harmonics compensation), but also the power of overproduction(by one power coefficient a fully sinusoidal) will inject into the grid. Finally, high-speed response and suitable dynamic performance of controller because of using both software and hardware control, compared to other controllers used, is a characteristic of the proposed method.

\section{Reference}

1. Santoso, Surya, Mark F. McGranaghan, and H. Beaty. Electrical power systems quality. McGraw-Hill, 2012.

2. Ferreira, Filipe, et al. "A control strategy for a three-phase four-wire shunt active filter." Industrial Electronics, 2008. IECON 2008. 34th Annual Conference of IEEE. IEEE, 2008.

3. Görbe, P., Attila Magyar, and Katalin M. Hangos. "THD reduction with grid synchronized inverter's power injection of renewable sources." Power Electronics Electrical Drives Automation and Motion (SPEEDAM), 2010 International Symposium on. IEEE, 2010. 
4. He, Jinwei, Md Shirajum Munir, and Yun Wei Li. "Opportunities for power quality improvement through DG-grid interfacing converters." Power Electronics Conference (IPEC), 2010 International. IEEE, 2010.

5. Singh, Mukhtiar, et al. "Grid interconnection of renewable energy sources at the distribution level with power-quality improvement features." Power Delivery, IEEE Transactions on 26.1(2011): 307-315.

6. Kamatchi Kannan, V., and N. Rengarajan. "Photovoltaic based distribution static compensator for power quality improvement." International Journal of Electrical Power \& Energy Systems 42.1(2012): 685-692.

7. Singh, Mukhtiar, and Ambrish Chandra. "Real Time Implementation of ANFIS Control for Renewable Interfacing Inverter in 3P4W Distribution Network." (2013): 1-1.

8. Bollen, Math HJ. "Characterisation of voltage sags experienced by three-phase adjustable-speed drives." Power Delivery, IEEE Transactions on 12.4 (1997): 1666-1671.

9. Schoene, Jens. "Evaluation of the Impact on Non-Linear Power on Wiring Requirements for Commercial Buildings." (2011).

10. E. W. Gunther, J. Rossman, "Application of Advanced Characterization Algorithms, UCA and Internet Communications Technology at the Point of Power Quantity and Quality Measurement," Conference Proceedings of EPRI PQA 1999.

11. Nguyen, Hoa M., and D. Subbaram Naidu. "Advanced control strategies for wind energy systems: An overview." Power Systems Conference and Exposition (PSCE), 2011IEEE/PES. IEEE, 2011.

12. Li, Wei. "Design of a hybrid fuzzy logic proportional plus conventional integralderivative controller." Fuzzy Systems, IEEE Transactions on 6.4 (1998): 449-463.

13. Zadeh, Lotfi A. "Fuzzy sets." Information and control 8.3 (1965).

14. Ciezki, John G., and Robert W. Ashton. PEBB Feedback Control Low Library. Volume 1: Three-Phase Inverter Control Algorithms. No. NPS-EC-99-002. NAVAL POSTGRADUATE SCHOOL MONTEREY CA DEPT OF ELECTRICAL AND COMPUTER ENGINEERING, 1999.

15. Rashid, Muhammad Harunur. Power electronics: circuits, devices, and applications. Pearson Education India, 2003.

16. Ilavarasi, V., and C. Christober Asir Rajan. "Power quality improvement in grid connected system using four leg VSI." Advances in Engineering, Science and Management (ICAESM), 2012 International Conference on. IEEE, 2012.

17. Patel, Mukund R. Wind and solar power systems: design, analysis, and operation. CRC press, 2005.

18. Salas, V., et al. "Review of the maximum power point tracking algorithms for standalone photovoltaic systems." Solar Energy Materials and Solar Cells90.11(2006): 15551578.

19. De la Rosa, Francisco. Harmonics and power systems. CRC Prese, 2006. 